\title{
- Encefalite Espongiforme Bovina: considerações epizootiológicas, etiológicas e clínicas
}

\section{- Bovine Spongiform Encephalopathy: epizootiology, etiology and clinical update}

Av. Prof. Dr. Orlando Marques de Paiva, 87

Cidade Universitária 05508-000 - São Paulo S.P. Tel: (011) 818-4218/4272

Fax (011) 818-4228

E-mail: ortolani@usp.br

\section{Enrico Lippi Ortolani - CRMV-SP n 2042}

Professor Associado do Departamento de Clínica Médica da Faculdade de Medicina Veterinária e Zootecnia da Universidade de São Paulo

\section{RESUMO}

Apresentam-se nesta revisão dados e informações básicas para a compreensão da encefalite espongiforme que grassa em bovinos de vários países europeus, em especial do Reino Unido, desde 1985. Descrevem-se de maneira sucinta aspectos ligados ao histórico, etiologia; quadro clínico, epizootiologia e implicações econômicas da referida enfermidade. Também são sugeridas medidas de controle, a serem mantidas ou adotadas, para certificar que a mesma continue a ser uma doença exótica em nosso país.

Unitermos: Encefalopatia espongiforme, Bovinos, Etiologia, Epizootiologia, Quadro clínico

\section{Introdução}

A Encefalite Espongiforme Bovina (EEB) foi descrita pela primeira vez, no Reino Unido, por WELLS et al. ${ }^{11}$ no ano de 1987 , porém os primeiros casos provavelmente surgiram no ano de 1985. Desde então, têm gerado grandes prejuízos econômicos e enorme esforço científico para a compreensão dos mecanismos da doença, assim como no empreendimento das medidas de controle da mesma. Por se tratar de uma zoonose, hoje, a EEB gera uma grande apreensão nas populações que convivem com o problema. A enfermidade é causada por um agente infeccioso não convencional (Príon) e tem caráter transmissível, porém não contagioso; a incubação do agente é longa, contudo o desenrolar do quadro clínico é de curta duração. Desde que o bovino seja acometido a evolução é fatal, não existindo, até o momento, tratamento para as graves lesões neurodegenerativas no Sistema Nervoso Central (SNC).

\section{Histórico}

1986 - Reconhecimento da doença, no sul da Inglaterra.

1987 - Primeira publicação no "The Veterinary Record" por WELLS et al. ${ }^{11}$

1988 - Após hercúleo trabalho epidemiológico, WILESMITH et al. ${ }^{12,13,14}$ constataram que a doença só ocorria em bovinos que ingeriam Farinha de Carne e Ossos (FCOs). Nem todas as FCOs provocavam a doença, apenas aquelas que eram provenientes de fábricas cujo processamento, para retirar o excesso de gordura, era realizado através do uso de calor e centrifugação, não ocor- 
rendo transmissão em farinhas tratadas com uso de solventes. Sugeriram ainda que os agentes priônicos contaminantes estariam nas FCOs que contivessem tecidos nervosos de ovinos acometidos por "Scrapie" (doença nervosa degenerativa, causada também por Príons). Isto decorreu da similaridade das lesões no SNC entre o Scrapie e EEB e pelo fato de rotineiramente serem enviadas para fabricação de FCOs carcaças de ovinos, independentemente da causa de morte.

1988 - Imediatamente, o Ministério da Agricultura, Pesca e Alimentos do Reino Unido proibiu o consumo de FCOs para ruminantes e passou a considerar a doença notificável (o veterinário que diagnostica este mal e não informa o Ministério pode perder sua Licença).

1990 - Surgimento de casos de EEB em outros países (Portugal, Suíça e Irlanda, entre outros), através da importação de gado britânico infectado e de FCOs contaminadas.

1990 - Brasil pró́be importação de ruminantes do Reino Unido.

1992 - Ano da ocorrência de maior número de casos de EEB no Reino Unido.

1995 - Com as medidas sanitárias tomadas diminui drasticamente a incidência de EEB, no Reino Unido.

1996 - Em março, dez pacientes jovens apresentaram a Doença de Creutzfeldt-Jacob Diferenciada (DCJD), num intervalo de 14 meses, no Reino Unido. Suspeitou-se que era proveniente da ingestão de carne bovina de animais com EEB.

- Em abril, o acordo de Florença, promovido pelo Mercado Comum Europeu (MCE), determina que o Reino Unido sacrifique os animais de grupo de risco, dos rebanhos com histórico de EEB.

- Em junho, o Ministério da Agricultura e Reforma Agrária proíbe o uso alimentar de FCOs para ruminantes, no Brasil.

- Em agosto, há demonstração experimental das primeiras evidências de transmissão vertical de EEB. ${ }^{1}$

1997 - Em setembro, Stanley Prusiner, pesquisador norte-americano, ganha o prêmio Nobel pelo estudo promissor e profundo sobre a estrutura química dos Príons.

- Em outubro, são publicadas na revista Nature ${ }^{2}$ comprovações que a cepa priônica de EEB é idêntica à da DCJD mas diferente da doença tradicional no ser humano, demonstrando o caráter zoonótico da enfermidade. A cepa priôni- ca de EEB é diferente da do "Scrapie" ovino.

1997 - Morte de 21 britânicos e 2 franceses com a DCJD.

1998 - O prejuízo acumulado ultrapassa a casa dos US\$ 3,00 bilhões de dólares.

\section{Etiologia}

Vírus, virino, transmissão hereditária (doença genética recessiva autossômica) foram algumas das suposições de agentes causais das encefalites espongiformes no homem e nos animais ${ }^{4}$ : DCJ, Kuru, Síndrome de Gerstmann-Sträusser-Scheinker, Insônia fatal familiar e Doença de Alpers nos seres humanos e EEB, Scrapie, EE dos felinos, Encefalopatia transmissível da marta, Doença crônica consumptiva dos cervos e Encefalite de ungulados exóticos nos animais. Todavia, através de vários experimentos ficou demonstrado que o agente causal é um Príon. Este termo foi utilizado pela primeira vez por PRUSINER $1982^{6}$ para descrever as "Proteinaceus Infection Particles". Como o termo Proín não soava bem na língua inglesa o propositante sugeriu Príon. Esta proteína tem ao redor de 250 aminoácidos (Peso 33-35 Kdaltons) e é quase idêntica a uma determinada proteína normalmente produzida pelas células do SNC, e que provavelmente tenha como função a neuro-transmissão. Ambas proteínas não contém DNA ou RNA e o que as diferencia é a estrutura química secundária (conformação espacial). Enquanto que o Príon contém $43 \%$ de suas ligações entre aminoácidos, em forma de folha pregueada $\beta$, a proteína autógena contém apenas $3 \%$ a $4 \%$ destas ligações. Os aminoácidos com ligação $B$ proporcionam à molécula forte estabilidade química e resistência. No caso dos Príons estes aminoácidos recobrem o resto da proteína como se fossem uma couraça. Isto torna a proteína altamente resistente aos principais agentes físicos e químicos. Assim, o Príon é resistente ao calor seco, $160^{\circ} \mathrm{C} / 24 \mathrm{~h}$ e autoclavagem $126^{\circ} \mathrm{C} / 2 \mathrm{~h}$ (proteínas normalmente coagulam-se a temperaturas superiores a $60^{\circ} \mathrm{C}$, às proteases gastrintestinais (tripsina, pepsina, nucleases, etc.), ao baixo $\mathrm{pH}$ (por exemplo do abomaso: 2,2), à radiação ultravioleta (até $2540 \mathrm{~A}$ ), à energia ultrassônica, à radiação ionizante (até $150 \mathrm{kD}$ ) e à maioria dos desinfetantes, inclusive formaldeído. Porém, não resistem aos solventes, ao hipoclorito de sódio ou à autoclavagem acima de $160^{\circ} \mathrm{C}$ (GODON ; HONSTEAD/1998) ${ }^{4}$.

Os Príons de Scrapie, provavelmente, não deram origem à EEB, pois a primeira enfermidade havia sido descrita no início do século 18 , e a inoculação experimental de Príons de Scrapie em bovinos havia gerado um quadro clínico diferente do observado na EEB. Acredita- 


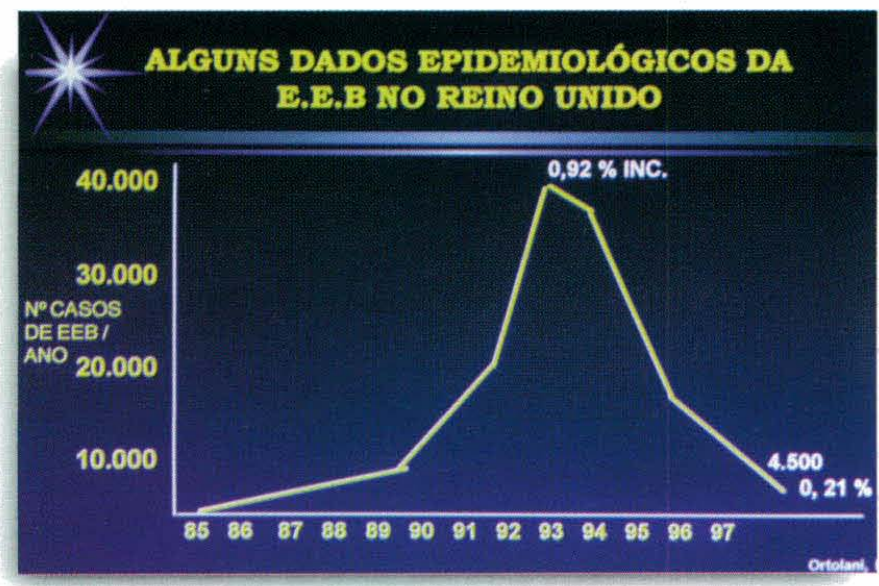

Figura 1 - Número de Casos de EEB ocorridos no Reino Unido, no decorrer dos anos 1985 e 1997. (Gráfico onde a abscissa apresenta a seqüência numérica dos anos e a ordenada o $\mathrm{n}^{\circ}$ de bovinos acometidos/ ano).

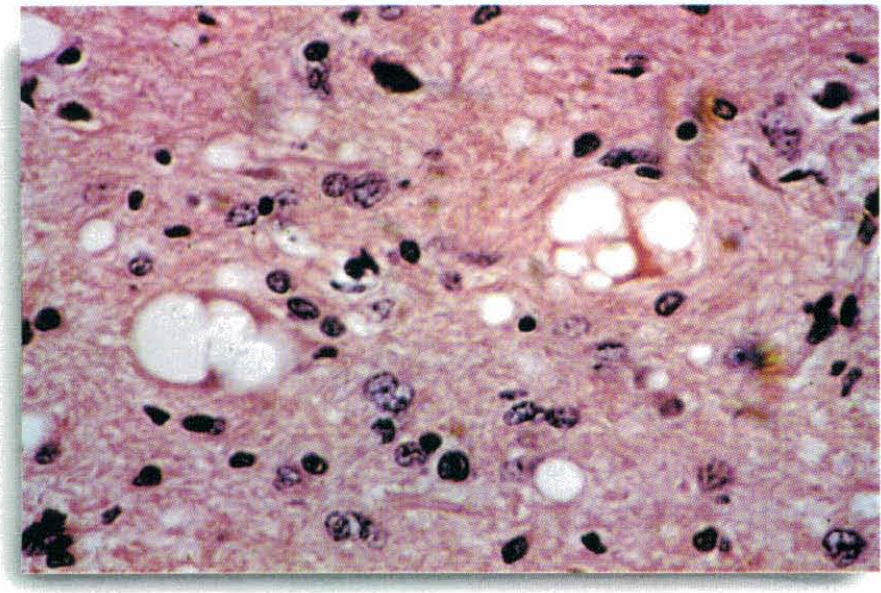

Figura 2 - Secção de Medula Oblonga de bovino com EEC corado pela Hematoxilina/Eosina. Notar as vacuolizações nos neurópilos da matéria cinzenta. Aumento de 400 vezes.

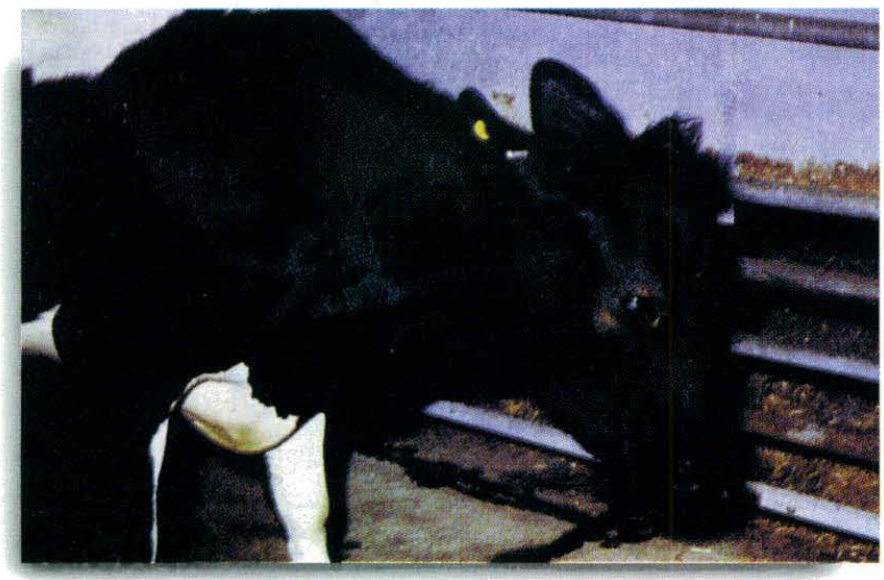

Figura 3 - Bovino apresentando EEB. Notar o estado de apreensão e o posicionamento baixo da cabeça. Este animal apresentava comportamento agressivo e grande dificuldade em adentrar a sala de ordenha

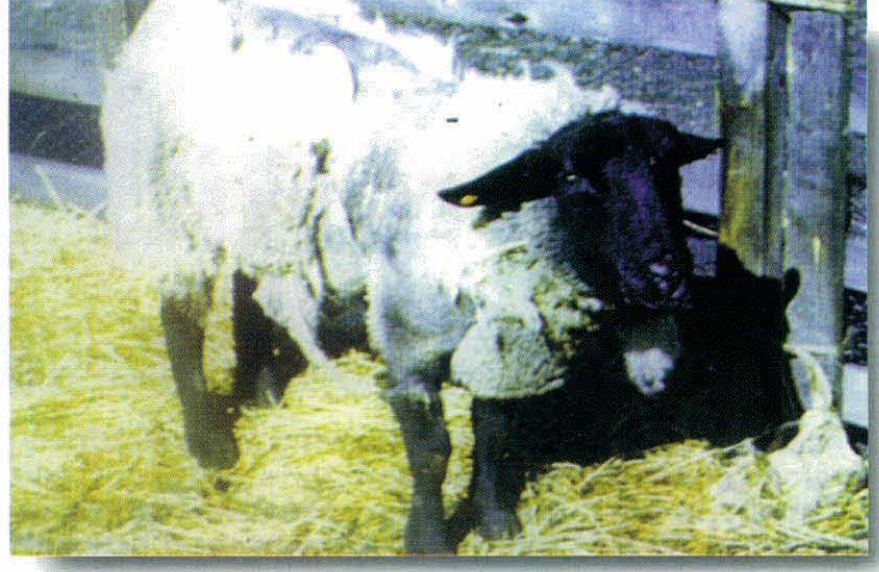

Figura 4 - Ovino com forma prurítica de Scrapie, apresentando alopecia em vastas áreas do flanco, região lombar e membro anterior

\section{Entenda como o Scrapie se manifesta}

O Scrapie pode ser disseminado por transmissão vertical e horizontal. Ovinos da raça Suffolk parecem ser mais predispostos. A incubação é longa, ao redor de três a quatro anos. A incidência em rebanhos acometidos varia de $1 \%$ até $50 \%$, principalmente em rebanhos que mantém ovinos idosos. Caprinos eventualmente podem apresentar Scrapie, em particular quando criados com ovinos infectados. Animais doentes inicialmente lideram ou caminham entre os últimos do rebanho. Alguns ovinos passam a enfrentar agressivamente pessoas e cães; outros tornam-se muito excitados ou angustiados quando manipulados. Parte dos doentes apresenta intensa depressão do estado geral. O quadro clínico pode evoluir para um dos dois síndromes específicos. No primeiro deles, o quadro é de prurido obsessivo, com perda extensiva de lã nos flancos, região lombar e nos membros como resultado de prolongada fricção em obstáculos e de automutilação. A natureza compulsiva deste comportamento pode levar ao desenvolvimento de lesões cutâneas. Ovinos afetados, também, podem apresentar tremores musculares finos e exibir o reflexo de mordiscamento. No outro síndrome o quadro típico é de incoordenação motora. Ovinos inicialmente se locomovem com passadas hipermétricas. Alguns animais apresentam andar com passadas de marcha militar, ou com trote duro. Com o evoluir do quadro o cambaleio do trem posterior é evidente e com facilidade o animal cai. Quando em estação muitos ovinos permanecem por longos períodos apoiados em postes ou outros obstáculos e quando obrigados a se locomover tem um andar de embriagado. Nesta fase o apetite diminui progressivamente e uma dramática perda de peso ocorre. Mesmo assim, animais com a doença instalada podem sobreviver por até 10 meses, mas a maioria sucumbe após as primeiras três a quatro semanas. 
se que o Príon de EEB tenha- se originado da mutação da própria proteína autógena e que o mutante tenha se multiplicado em um bovino. Em seguida este animal deve ter sido utilizado na fabricação de FCOs, sendo fonte contaminante original.

Um grama de SNC contaminado é suficiente para infectar um bovino (GODON; HONSTEAD, $1998{ }^{4}$ ). O Príon ingerido permanece na placa de Peyer, no íleo posterior, por 6 a 10 meses, distribuindo-se em seguida aos órgãos linforeticulares (baço, tonsilas, linfonodos etc). Só a partir do $32^{\circ}$ mês pós-infecção os Príons atingem a medula oblonga e os nervos periféricos, migrando pelo SNC na velocidade de $1 \mathrm{~mm} / \mathrm{dia}$ (WELLS et al., 199811). Os Príons entram nas células nervosas e se reproduzem, sem cessar, utilizando o mesmo sistema multiplicador da proteína autógena. Os chaperones (sistema celular responsável pela inspeção da conformação espacial das proteínas produzidas) são devidamente "ludibriados"; assim os Príons continuam a serem produzidos pelas células nervosas. Os Príons acumulados juntam-se formando fibrilas, as quais comprimem as organelas no citosol até a morte celular (PRUSINER, $1997^{7}$ ). Devido à vacuolização neuronial, segmentos do SNC, corados pela Hemotoxilina/Eosina (H\&E) examinados ao microscópico com aumento maior, dão a impressão de se tratar de esponja ou "queijo suíço". Os Príons são reconhecidos como proteínas autógenas, não estimulando a formação de anticorpos.

\section{Quadro Clínico}

O quadro clínico de EEB surge subitamente e tem evolução subaguda, levando cerca de 30 dias, desde o início dos sinais até a morte, na maioria dos casos. Contudo, alguns animais têm evolução lenta, com duração de até um ano. As mudanças de comportamento são as primeiras manifestações a ocorrerem, na seguinte ordem: os animais tornam-se mais apreensivos, relutam em passar por estreitamentos (portas de salas de ordenha e porteiras), separam-se do rebanho, exibem exagerada movimentação do pavilhão auricular, bruxismo, lambem continuamente os flancos e narinas, apresentam hiperestesia ao som, frenesi, e quando manipulados respondem agressivamente com vigorosos coices (WELLS et al., 198710, WILESMITH et al., 198812). Assim, animais normalmente tranquiilos, podem se tornar agressivos e excitados. Este quadro sintomatológico levou os tablóides britânicos, sensacionalistas, a denominarem a EEB, de maneira grosseira, como "doença da vaca louca".

As grandes funções não se apresentam alteradas; mas bradicardia e menor freqüência de ruminação ocorrem em cerca de $20 \%$ dos animais. O apetite só diminui no quadro terminal, devido à dificuldade de preensão dos alimentos. Todavia, cerca de $75 \%$ de vacas com EEB diminuem a produção láctea e perdem rapidamente peso.

As alterações de postura e movimentação são evidentes e variam de acordo com a evolução das lesões no SNC. O quadro se inicia com passadas hipermétricas, ligeiro cambaleio do trem posterior e finos tremores musculares. Com o evoluir do quadre os bovinos têm incoordenação motora, passadas curtas, inépcia para girar, caem com facilidade e têm dificuldade de se levantar, devido à ataxia dos membros posteriores. $\mathrm{O}$ decúbito prolongado precede a morte. Ocasionalmente, alguns animais passam a andar em círculos, apresentam meneios de cabeça ou posicionam-na sempre para baixo, sialorréia, lacrimejamento e emissão de gemidos roucos. Embora em ovinos com Scrapie o quadro pruriginoso seja predominante e intenso, em bovinos com EEB ocasionalmente isto ocorre. Em ovinos, quando se massageia a região lombo-sacral os animais apresentam estiramento do pescoço e movimentos constantes de lábios e língua (reflexo de mordiscamento). Além deste reflexo, os bovinos podem, também, exibir contínuo roçar da cabeça com os cascos dos membros posteriores (WILESMITH et al., $1988{ }^{12}$ ).

Com o quadro clínico já instalado, deve-se procurar manter os animais em ambiente que lhes seja familiar e silencioso a fim de reduzir a severidade dos sinais, em especial a hiperestesia (WILESMITH et al. $1988{ }^{12}$ ).

A gênese dos sinais nervosos está ligada às lesões no SNC. A hipersensibilidade, frenesi, agressividade e tremores musculares são decorrentes de lesões no cortex cerebral. As alterações de postura, marcha e coordenação motora estão relacionadas à disfunção no núcleo vestibular e no cerebelo. Possivelmente, a bradicardia esteja ligada às lesões do nervo vago ou mesmo do tronco encefálico.

O diagnóstico diferencial deve ser feito com uma série de doenças infecciosas, (raiva, listeriose, doença de Aujeszky, abcessos cerebroespinais), metabólicas (hipomagnesemia, forma nervosa de hipoglicemia e hipocalcemia), nutricionais (poliencefalomalácia por deficiência de vitamina $B_{1}$ e intoxicação pelo enxofre), assim como com algumas intoxicações (plumbismo, toxinas tremogênicas etc) (RADOSTITS et al. $1994^{8}$; KITCHING, 19975).

O diagnóstico é feito através do exame histopatológico de tecidos do tronco encefálico, que apresentam vacuolização intracitoplasmática dos neurônios e dos neurópilos da substância cinzenta, com distribuição simétrica e bilateral, associada à ausência de resposta inflamatória. Em relação a futuras possibilidades de trata- 
mento e prevenção PRUSINER $\left(1997^{7}\right)$ sugeriu o desenvolvimento de drogas que pudessem quelar ou desestabilizar a multiplicação dos Príons ou a seleção de bovinos com código genético resistente à doença, já que ovinos com a presença de arginina/arginina no codon 171 são resistentes ao Scrapie.

Como no Brasil ainda não foi descrita a presença de EEB, devem continuar a ser mantidas medidas preventivas, para minimizar o risco de aparecimento da doença em bovinos e seres humanos, tais como: a proibição de importação de bovinos de países onde persiste a endemia (Reino Unido, Suíça e Portugal) e o uso de FCOs para ruminantes. Medidas devem ser tomadas pelo Ministério de Agricultura e Reforma Agrária, para que todo bovino, com idade superior a um ano de idade, que manifeste quadro sintomatológico nervoso e que tenha evolução fatal, semelhante ao apresentado pela EEB, tenha seu SNC (mais em especial, de tecidos do tronco encefálico) enviado para exame histopatológico diferencial, em centros de referência de diagnóstico. Casos esporádicos de Scrapie foram constatados, nesta última década, em ovinos, da raça Suffolk, no Estado do Rio Grande do Sul. Assim, vigilância epidemiológica especial deve ser assumida, para a erradicação desta enfermidade entre os nossos rebanhos ovinos.

\section{Epizootiologia}

Até o momento cerca de 99,8\% dos casos de EEB ocorreram no Reino Unido. Segundo dados oficiais, até agosto de 1997, foram notificados 167.306 casos de EEB em 34.128 fazendas, ou seja em $67 \%$ e $15,5 \%$ dos rebanhos leiteiros e de corte britânicos, respectivamente. A incidência atingiu 0,92\% do gado adulto, em 1992, e em 1996 caiu para $0,17 \%$. A letalidade é máxima, ou seja, todos animais acometidos evoluem para a morte. Casos de EEB também já foram detectados na Suíça (228), Irlanda (188), Portugal (61), França (31), Alemanha (5), Itália e Oman (2), Canadá, Dinamarca e Malvinas (1). $\mathrm{Na}$ grande maioria destes países os casos surgiram a partir da importação de gado ou de FCOs do Reino Unido (GODON; HONSTEAD, 19984). No Brasil não foi descrito nenhum caso em bovinos.

O período médio de "incubação", desde a infecção até o aparecimento dos primeiros sinais clínicos, é de cinco anos (WELLS et al., 199811). O risco de infecção é semelhante em machos e em fêmeas, assim como nas mais variadas raças e cruzamentos bovinos criados no Reino Unido (WILESMITH et al. 1988 ${ }^{12}$ ).

A infecção na quase totalidade dos casos ocorreu pela ingestão de FCOs contaminadas com os Príons. Até o ano de 1978 a grande maioria da fábricas de FCOs utilizava solventes para retirada de gordura. Para baratear o processo, em 1981 cerca de $90 \%$ das fábricas passaram a utilizar o calor úmido (média de $129^{\circ} \mathrm{C}$ ) em substituição aos solventes. Cerca de quatro anos após os primeiros casos clínicos surgiram. Na Escócia, onde a grande maioria de FCOs era produzida pelo processo antigo, menos de $6 \%$ dos rebanhos estavam infectados. Inversamente, em certas regiões do sul da Inglaterra até $90 \%$ dos rebanhos leiteiros apresentavam um ou mais casos de EEB (WILESMITH et al., 1988 ${ }^{12}$, 1991'13, $1992^{14}$ ).

Estudos recentes constataram que existe um risco de cerca de $10 \%$ de transmissão vertical, em vacas nos últimos seis meses do seu período de incubação (BSE research, 1996) Contudo, vacas com estágio avançado de EEB apresentam infertilidade. Em ovinos com Scrapie a transmissão vertical ocorre, provavelmente, por ingestão, pelo feto, de fluido amniótico contaminado com Príons (KITCHING, 19975). Sangue, sêmen, leite, urina, saliva, lágrima e a própria carne não transmitem a doença. Transmissão horizontal ainda não foi comprovada.

\section{Implicações econômicas}

Esta doença causou um enorme prejuízo econômico para a pecuária britânica. Todos os bovinos com sinais clínicos da doença foram sacrificados. Posteriormente, bovinos adultos, do grupo de risco, de propriedades em que foram constatados casos EEB, também foram sacrificados. Devido à obrigatoriedade do abate, os proprietários receberam uma compensação econômica pelo sacrifício, em média, ao redor de US\$1000,00/cabeça. Até o momento cerca de 1.300 .000 bovinos já foram sacrificados (UNITED KINGDOM, $1996{ }^{9}$ ).

As exportações de carne, gado, embriões, sêmen e todos os produtos que sejam de origem bovina (inclusive cosméticos) deixaram de ser realizadas pelo Reino Unido; por outro lado, foram importados mais US\$200 milhões em bovinos de reposição. Os gastos com esquemas de vigilância não são conhecidos, porém estima-se que sejam bastante altos. A partir de julho de 1996 todos os bovinos transportados dentro do Reino Unido necessitam de um "passaporte" de acompanhamento da vigilância sanitária. Assim, o Ministério pode rastrear animais vendidos ou identificar os sacrificados em matadouros. Em apenas um ano de vigilância mais de três milhões de "passaportes" foram emitidos (BENNETT; HALLAM, $1998{ }^{1}$ ).

Nos anos de 1996 e 1997 na Alemanha e na Itália o consumo de carne bovina diminuiu cerca de $50 \%$. Con- 
ORTOLANI, ENRICO LIPPI. Encefalite Espongiforme Bovina: considerações etiológicas, clínicas e epizootiológicas. Revista de Educação Continuada do CRMV-SP / Continuous Education Journal CRMV-SP. São Paulo, Volume 2, fascículo 1, p. 3 - 8, 1999.

tudo, grande parte dos consumidores que se abstiveram de carne bovina substituíram-na pela de frango ou de suínos. O preço do gado bovino diminuiu cerca de $20 \%$ no Reino Unido e $15 \%$ nos outros países do MCE. (BENNETT; HALLAN $1998^{1}$ ). O turismo no Reino Unido, desde 1996 , caiu cerca de $2 \%$.

\section{Considerações Finais}

A ocorrência do surto de EEB associada ao desenvolvimento das técnicas de clonagem foram, de longe, os principais fatos científicos na Medicina Veterinária nestas últimas duas décadas. Agora, novos desafios surgem na compreensão dos mecanismos intrínsecos desta inédita doença, assim como no seu controle.

A descoberta e caracterização estrutural dos Príons abre uma nova página no vasto capítulo da Microbiologia, exigindo que esta ciência seja reanalisada e reclassificada, à luz dos novos conhecimentos ou seja: pela comprovação da existência de agentes infecciosos não convencionais (não tem DNA ou RNA), que apresentam nova forma de multiplicação no organismo do hospedeiro, e pelos métodos ardilosos de driblar quaisquer formas de defesa do enfermo.

\section{SUMMARY}

A review on bovine spongiform encephalophaty (BSE), that has been occurred since 1985 in Europe mainly in the United Kingdom, is presented. Topics such as history, etiology, clinical signs, epizootiology and economical implications are described. The control measures to minimize any risk of establishment of BSE in Brazilian cattle are suggested.

Uniterms: Spongiform encephalopathy, Bovine, Etiology, Epizootiology, Clinical signs

\section{BIBLIOGRAFIA DE APOIO}

1. BENNETT, R.M.; HALLAM, D. Implications of BSE policy for livestock production and veterinary service in the United Kingdom. Veterinary Record, v.142, n.7 p.155-9, 1998.

2. BRUCE, M.E.; WILL, R.G.; IRONSIDE, J.W.; McCONNELL, I.; DRUMMOND, D. Transmissions to mice indicate that "new variant" CJD is caused by the BSE agent. Nature v.389, p.498-501, 1997.

3. BSE research. results suggest enhanced risk of maternal transmission. Veterinary Record, v.136,n.6, p.126-7, 1996.

4. GODON, K.A.H; HONSTEAD, J. Transmissable spongiform encephalithies in food animals. Veterinary Clinics of North America, v.14, n.1, p.49-70, 1998.

5. KITCHING, P. Notifiable viral disease and spongiform encephalopathies of cattle, sheep and goats. In Practice, v.19, n.2, p.51-63, 1997.

6. PRUSINER, S.B. Novel proteinaceus infectious particles cause scrapie. Science. v.216, p. 136-44, 1982.

7. PRUSINER, S.B. Prion diseases and the BSE crisis. Science, v.278, p.245-51, 1997.

8. RADOSTITS, O.M.; BLOOD, D.C.; GAY, C.C. Veterinary Medicine. ed., Londres; Bailière Tindall, 1994, 1763p.

9. UNITED KINGDOM MINISTRY OF AGRICULTURE, FISHERIES and FISH. Bovine spongiform in Great Britain: A progress report november, 1996. London, MAFF, 1996. $53 \mathrm{p}$.

10.WELLS, G.A.H.; SCOTT, A.C.; JOHNSON, C.T.; GUNNING, R.F.; HANCOCK, R.D.; JEFFREY, M.; DAWSON, M.; BRADLEY, R. A novel progressive Spongiform Encephalopathy in cattle. Veterinary Record, v.121, n.18 p.419$420,1987$.

11.WELLS, G.A.H.; HAWKINS, R.B.; GREEN, A.R.; AUSTIN, I; DEXTER, I; SPENCER, Y.I.; CHAPLIN, M.J; STACK, M.J.; DAWSON, M.;. Preliminary observations on the pathogenesis of experimental bovine Spongiform (BSE): an update Veterinary Record, v.142, n.4, p.103-6, 1998.

12.WILESMITH, J.W.; WELL, G.A.G; CRANWELL, M.P.; RYAN, J.B.M. Bovine Spongiform Encephalopathy: Epidemiological studies, Veterinary Record, v.123, n.25, p.638-644, 1988.

13.WILESMITH, J.W.; RYAN, J.B.M.; ATKINSON, M.J. Bovine Spongiform Encephalopathy: epidemiological studies on the origin. Veterinary Record, v.128, n.9, p.199-203, 1991.

14.WILESMITH, J.W.; RYAN, J.B.M.; ATKINSON, M.J. Bovine Spongiform Encephalopathy: epidemiological features 1985-1990. Veterinary Record, v.130, n.4, p.90-94, 1992. 